\title{
Charpy test investigation of the influence of fabric weave and fibre nature on impact properties of PEEK-reinforced composites
}

\author{
Olivier De Almeida', Jean-François Ferrero², \\ Laurent Escalé ' and Gérard Bernhart'
}

\begin{abstract}
The aim of the work is to use Charpy impact test for quick evaluations of different Polyether-ether-ketone (PEEK)-reinforced composites to be used for impact protection. In the first part, the influence of weave pattern was first analysed by comparing the impact behaviour of three PEEK composites reinforced with plies of unidirectional (UD) tapes, $5 \mathrm{H}$ satin fabrics and $2 \times 2$ twill fabrics made of high-strength carbon fibres. In the second part, the influence of fibre nature was investigated for the same weave pattern. The impact behaviour of five $2 \times 2$ twill fabrics made from inorganic fibre (carbon, glass and basalt) and organic fibre (aramid and poly(p-phenylene-2,6-benzobisoxazole) (PBO)) has been compared. Two main types of failure modes were identified: a brittle behaviour mode with high failure strength and a highly deformable behaviour mode in which energy absorption is more important. The balance between brittle behaviour and highly deformable behaviour results from competition between the yarn crimp, weave pattern and fibre properties of the composite. Slight yarn crimp and small ply thickness increase the stiffness of the composite and induce brittle behaviour characterized by fibre failure in tension and a steep peak on the loading curves. This behaviour is observed in UD and $5 \mathrm{H}$ satin carbon-reinforced composites or $2 \times 2$ twill glass and basalt fabric-reinforced composites. In contrast, aramid and PBO $2 \times 2$ twill fabric composites exhibit high shear strength. The highly deformable behaviour of the specimens during the Charpy impact
\end{abstract}

\footnotetext{
' CNRS, Mines Albi, INSA, UPS, ISAE, ICA (Institut Clement Ader), Université de Toulouse, Albi, France

${ }^{2}$ CNRS, UPS, Mines Albi, INSA, ISAE, ICA (Institut Clement Ader), Université de Toulouse, Toulouse, France

\section{Corresponding author:}

Jean-François Ferrero, CNRS, UPS, Mines Albi, INSA, ISAE, ICA (Institut Clement Ader), Université de Toulouse, II8, Rte de Narbonne, F-31062 Toulouse, France.

Email: jean-francois.ferrero@univ-tlse3.fr
} 
led, in the case of organic fibres, to a non-breakage of the fibres and consequently to a high level of energy absorption. This behaviour is necessarily interesting in armour applications.

\section{Keywords}

Thermoplastic composites, impact, Charpy test, fibre nature, yarn crimp effect

\section{Introduction}

Composites are extensively used in aerospace applications due to their high strength to weight ratio. However, one of the major concerns is their susceptibility to impact damage, generally due to assembly or maintenance activities (handling, storage and accidental tool drops). The effect of foreign object impact can severely degrade the strength of composite structures while being undetectable by visual inspection. ${ }^{1}$

Many researchers have investigated the brittle behaviour of unidirectional (UD) carbon epoxy plates. It is strongly dependent on the matrix cracking, which plays an important role in its progressive failure mode. Among the many studies that have tried to explain the different types of damage developing in a composite laminate plate during a low velocity/low energy impact, ${ }^{1-3}$ many works propose a scenario of impact damage, which gives matrix cracks a precursor role in the development of the delamination in the laminates. This scenario begins with the development of matrix cracks in the impact zone below the impactor. These cracks increase during loading following the fibre direction and can induce delamination in the interply area. This behaviour is particularly observed for continuous fibre-reinforced thermosetting composites that have been intensively used over the past three decades in aeronautical applications. ${ }^{1}$ High-performance thermoplastic resin (e.g. PEEK) offers a promising alternative to thermosetting resins because of its better resistance to impact damage. ${ }^{4-6}$ Many efforts have been made to understand why such materials are often more damage tolerant. The most studied configuration remains PEEK resin-reinforced carbon fibre, such as AS4/APC2 or AS4/APC1 (for the older studies) UD prepreg. ${ }^{7}$ Drop weight impact produced less extensive damage in carbon/PEEK fibre laminates. ${ }^{8-10}$ Because of the less extensive damage and greater delamination fracture energy, the residual compressive strengths were significantly greater with a PEEK matrix. For carbon/PEEK fibre woven ply laminates, a recent contribution can be found in the study by Vieille et al. ${ }^{11}$ where the impact behaviour of a thermosetting-based (epoxy) and two thermoplastic-based (PEEK and polyphenylene sulfide [PPS]) laminates is compared. From this work, it seems that the matrix plastic yielding plays an important role by locally promoting permanent deformation and, therefore, reducing the extent of damage.

All these failure modes under low-velocity impact loading conditions are strongly dependent on the fibre type, resin type, fibre-resin interface, loading velocity and projectile type. For low-velocity impact events, the use of pendulums like those employed in the Charpy test, drop towers or drop weights has become standard. ${ }^{1}$ Nevertheless, these 
two test methods have different objectives that are related to the specificity of the specimen used. The drop tower is typically used to impact plates. ${ }^{12-14}$ This allows observations of the evolution of the damage in the plane of the specimen (matrix cracking, debonding at the fibre-matrix interface and particularly ply delamination) created by the drop weight according to the stacking sequence studied. The damage is then equivalent to that created by the fall of a tool or a slight impact on a composite structure.

Many researchers have used the Charpy test to investigate the impact behaviour of various composite material structures. It allows the energy absorbing capability and the strength of the laminates to be estimated over the entire phase of loading and subsequent failure of the specimen. ${ }^{15-19}$ For this, it is necessary to use measurement chains of sufficiently high frequency response and striker tups of sufficiently high sensitivity. ${ }^{20}$ Hufenbach et al. ${ }^{21,22}$ have experimentally investigated the influence of major parameters, such as fibre type and architecture, hybrid composite and fibre orientation, on the impact damage resistance of composite structures. Ghasemnejad et al. ${ }^{23,24}$ have studied the energy absorbing capability of a delaminated hybrid composite beam (glass/epoxy and carbon epoxy) and delaminated fibre-reinforced polymer pinned using natural flax yarn. Fernandez-Canteli et al. ${ }^{25}$ have investigated the effect of ageing on the dynamic fracture toughness of three different fibre fabric composite laminates. They showed that ageing significantly affects the dynamic fracture toughness but had less effect on the fracture toughness.

The purpose of this study is to experimentally investigate the influence of different parameters like fibre nature or weave pattern on the impact properties of PEEK matrix composites by means of Charpy impact tests. In the first part, special emphasis is placed on the comparison between 1D and 2D carbon fibrous architectures and the second part aims at comparing the impact behaviour of inorganic-based (carbon, glass and basalt) and organic-based (aramid and poly(p-phenylene-2,6-benzobisoxazole) (PBO)) reinforcements of the same weave.

\section{Experiments}

\section{Materials}

Three different quasi-isotropic carbon/PEEK laminates were first investigated. These composite laminates essentially differ in the reinforcement weave pattern. The first material was prepared with 40 plies of AS4/APC2 tapes, provided by Cytec, using a quasi-isotropic lay-up $[90 / 45 / 0 /-45]_{5 \mathrm{~s}}$. The fibre volume fraction and nominal thickness of the UD prepreg tapes were, respectively, $60 \%$ and $0.137 \mathrm{~mm}$. After consolidation in a hot press at $395^{\circ} \mathrm{C}$ for $25 \mathrm{~min}$, the laminate thickness was $5.4 \mathrm{~mm}$. The second material was a carbon/PEEK laminate prepared with 16 plies of Pi-Preg ${ }^{\circledR}$ semi-preg provided by Porcher Composites. This semi-preg is a two-face powdered carbon fabric (high tenacity carbon fibres [HTA] carbon fibres, 5H satin weave, Reference 3106-P17) having a nominal ply thickness after consolidation of $0.31 \mathrm{~mm}$ and a fibre volume fraction of $50 \%$. The consolidation of this $[90 / 45 / 0 /-45]_{2 \mathrm{~s}}$ lay-up laminate was performed in a fast heating and cooling press for $10 \mathrm{~min}$ at $400^{\circ} \mathrm{C}$. The laminate thickness was $5.0 \mathrm{~mm}$. The 
Table I. Characteristics of the fabrics.

\begin{tabular}{lccccc}
\hline & Carbon & Glass & Basalt & Aramid & PBO \\
\hline Supplier & Hexcel & Brochier & Flocart & Teijin & Toyobo \\
Areal weight $\left(\mathrm{g} / \mathrm{m}^{2}\right)$ & 280 & 195 & 220 & 220 & 230 \\
Thickness $(\mathrm{mm})$ & 0.28 & 0.20 & 0.16 & 0.28 & 0.27 \\
\hline
\end{tabular}

PBO: poly(p-phenylene-2,6-benzobisoxazole).

Table 2. Film stacking configurations and laminate characteristics.

\begin{tabular}{lccccc}
\hline & Carbon & Glass & Basalt & Aramid & PBO \\
\hline Number of fabrics & 16 & 32 & 32 & 16 & 16 \\
Number of films & 64 & 64 & 64 & 64 & 64 \\
Thickness (mm) & 5.1 & 5.2 & 5.2 & 5.0 & 5.0 \\
\hline
\end{tabular}

PBO: poly(p-phenylene-2,6-benzobisoxazole).

third material was prepared by a film stacking technique using $38 \mu \mathrm{m}$ thick Victrex Aptiv 2000 films (grade 150) and a $2 \times 2$ twill carbon fabric. The dry carbon fabric had an areal weight of $280 \mathrm{~g} / \mathrm{m}^{2}$ and was provided by Hexcel under the reference HexForce 46285 . The $[90 / 45 / 0 /-45]_{3 \mathrm{~s}}$ laminate lay-up was made by alternating 64 films of PEEK and 16 plies of carbon fabric, which corresponded to a nominal fibre volume fraction of $50 \%$. As for the second composite, a fast heating and cooling press was used to perform the composite consolidation. A final thickness of $4.9 \mathrm{~mm}$ was obtained after processing the stacked sequence at $400^{\circ} \mathrm{C}$ for $20 \mathrm{~min}$.

In order to analyse the influence of fibre nature on the impact resistance of PEEK matrix composites, the $2 \times 2$ twill carbon-reinforced laminate was compared with four other composites prepared with $2 \times 2$ twill fabrics made of glass, basalt, aramid and PBO fibres. The characteristics of the fabrics are summarized in Table 1: although all the fabrics had the same weave, they exhibited different nominal thicknesses because of different areal weights.

Therefore, different numbers of plies were used to manufacture $5 \mathrm{~mm}$ thick plates with a fibre volume fraction of 50\%. In particular, glass- and basalt-reinforced composites were composed of 16 layers of $2 \times 2$ twill fabrics, while carbon, aramid and PBO composites were made with 32 layers of $2 \times 2$ twill fabrics (Table 2 ).

All composites were consolidated using the same methodology and processing conditions as for the carbon-reinforced composite described previously, that is, consolidation was performed in a fast heating and cooling mould at $400^{\circ} \mathrm{C}$ for $20 \mathrm{~min}$.

\section{Charpy test}

The interest of Charpy tests is that they only require test specimens of small dimension, such as beams, and, as it involves high energy impacts, they generate much more damage than those obtained with the other low-velocity impact tests. Although this test does not 


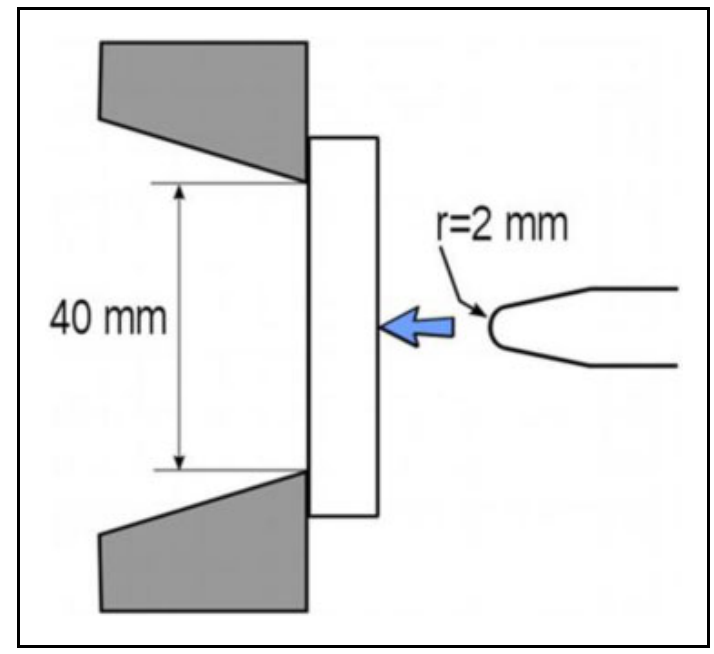

Figure I. Schematic drawing of the Charpy test device used in this study.

give data that can be used for absolute and quantitative strength calculations, they allow valuable comparative data that are determined in a simple and effective manner.

A Zwick Roell Charpy test device was used to investigate the impact damage resistance of the composite laminate structures. All the Charpy tests were carried out with a mass of pendulum of $21.9 \mathrm{~kg}$, a swing length of $748.6 \mathrm{~mm}$ and a height of 1400 $\mathrm{mm}$, which resulted in an impact speed of $5.2 \mathrm{~m} / \mathrm{s}$ and an impact energy of $300 \mathrm{~J}$. All the specimens were $70 \mathrm{~mm}$ long and $10 \mathrm{~mm}$ wide and were simply supported by anvils with a $40 \mathrm{~mm}$ support span (Figure 1).

No notches were machined on the specimens, contrary to what is conventionally done for the characterization of metallic Charpy samples. Indeed, in the present study, the Charpy impact tests performed do not aim at characterizing the fracture toughness but are only used as a reproducible experiment for comparison of impact behaviour of various composite materials.

The loading force $F(t)$ acting on the tip of the striking hammer during the failure process was measured by a force transducer located on the striker of the Charpy hammer. Energy losses due to bearing friction and air resistance were disregarded because of their small contribution to the energy balance.

At least five specimens of each type were tested. The force-displacement curves of five specimens of AS4/APC2 are shown in Figure 2. It can be seen that the impact behaviour is perfectly reproducible and, for clarity of curve comparisons, only one representative curve will be presented for each type of specimen.

After Charpy tests, a post-mortem analysis of the damaged specimens was carried out using optical microscope and/or visual observations.

\section{Results and discussion}

\section{Charpy data analysis}

Figure 3 shows a representative set of data obtained for the AS4/APC2 specimen. The energy absorbed over time (respectively hammer displacement) was obtained by 


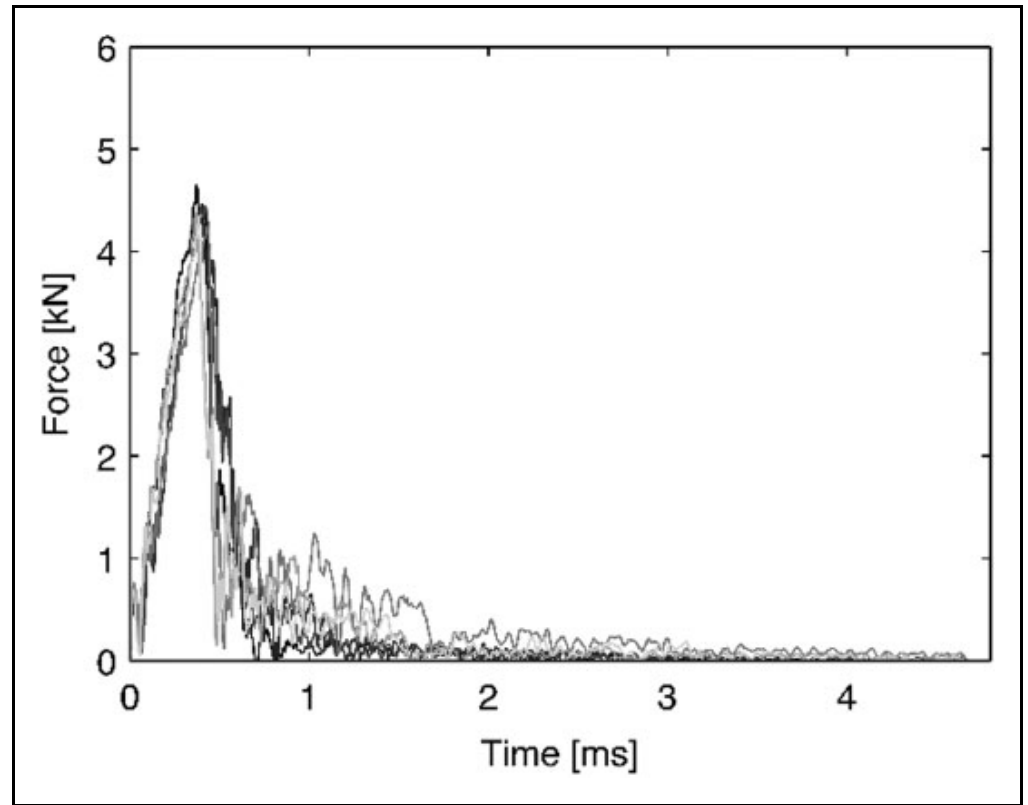

Figure 2. Load curves of Charpy testing on five specimens of the UD carbon/PEEK composite. UD: unidirectional.

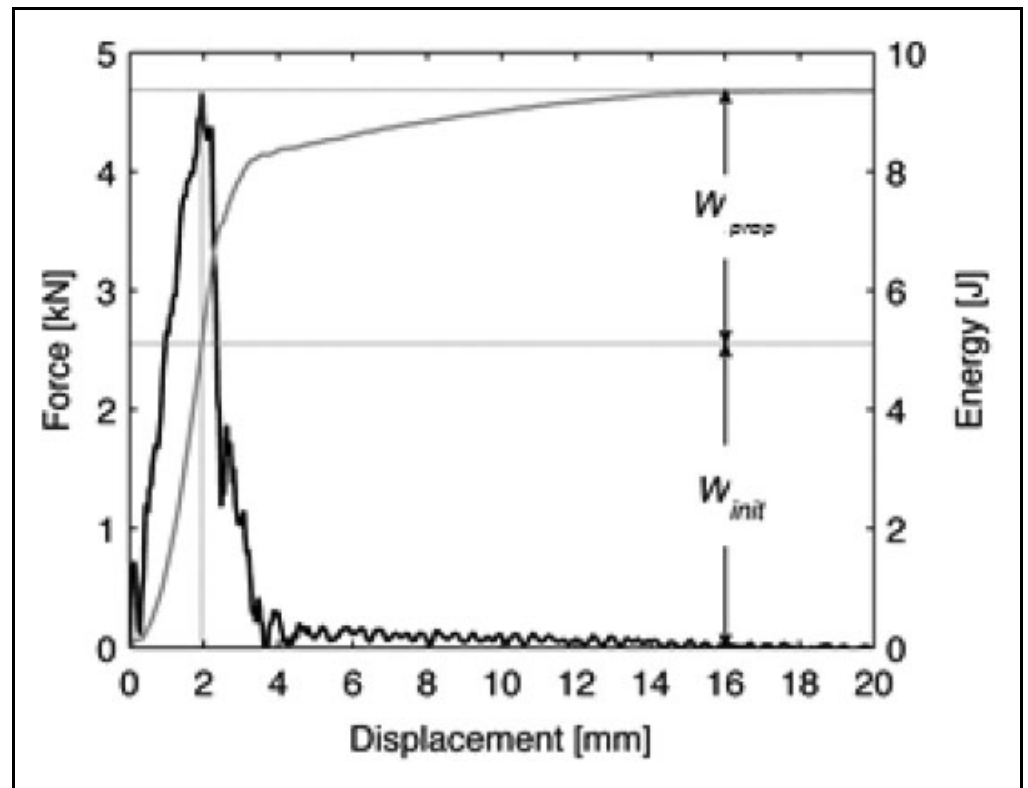

Figure 3. Typical set of instrumented Charpy impact data measured on APC2/AS4 specimen: measured force-displacement and calculated energy-displacement.

a double integration of the loading force over time. The entire loading and failure process of the specimen, that is, up to the displacement (respectively time) at which the loading force had decreased to zero force value again, represents the total energy for damaging and for breaking the specimen. This energy agrees with the one that would be determined from the difference in the heights of the striker before and after the test. 
The characteristic force-displacement curve exhibits a first loading phase corresponding to an energy $W_{\text {init }}$ absorbed by the specimen until the load has reached its maximum value $F_{\max }$. $W_{\text {init }}$ represents a quantity of the energy associated with the initiation of failure, through different damage mechanisms.

The second part of the curve ( $W_{\text {prop }}$ ) is the quantity of energy that is required to totally or partially break the specimen until it is ejected out of the anvils. This partial energy usually characterizes the energy used for crack propagation, generally related to the main mechanisms, that is, matrix microcracking, delamination and fibre fracture.

\section{Influence of weave pattern}

Results. The influence of weave pattern was first analysed by comparing the impact behaviour of three PEEK composites reinforced with plies of UD tapes, 5H satin fabrics and $2 \times 2$ twill fabrics made of high-strength carbon fibres. The measured Charpy impact data (force and energy over hammer displacement), photographs of broken specimens and schematic representation of the fibres breakage are shown in Figure 4.

For all three materials, Charpy impact tests led to complete fracture of the specimens, that is, the fracture of all carbon fibres through the specimen depth.

The force-displacement and energy-displacement curves reveal significant differences in the impact behaviour of the different weave patterns. The initial slope of the curves shows that the material stiffness of APC2/AS4 composite (Figure 4(a)) is higher than $5 \mathrm{H}$ satin (Figure 4(b)) and $2 \times 2$ twill composites (Figure 4(c)).

The load curves of UD- and satin-reinforced laminates are both characterized by a steep rise to a loading peak followed by an instantaneous drop of the applied force corresponding to the failure of the sample.

For both materials, $F_{\max }$ corresponds to a critical damage accumulation leading to the instantaneous failure of the fibres of the specimens. For the $2 \times 2$ twill laminate (Figure $4(c))$, the force-displacement curve still has a main loading peak at $F_{\max }$ but its level was only a quarter of that of the AS4/APC2 laminate. Moreover, the rupture of the specimens was not as brittle as for the other two materials.

The analysis of the tested samples shows differences in the damage mechanisms and fracture type. Ply delamination occurred once or twice in each sample of AS4/APC2 laminate on all or part of the surface of the specimens. Overall, the two other carbon fabric-reinforced composites do not show delamination. Only the last interface opposite to the impacted side is slightly delaminated over a very short length. The shape of the fibres failure shows a bending failure for the UD-reinforced laminate specimens (fibres breaks in the axis of the impact) and shear failure for the woven specimens (fibres breaks oriented at $45^{\circ}$ in the shearing cone).

As shown in Figure 5, due to the brittle behaviour, the loading phase largely contributes to energy absorption for both UD and satin fabric-reinforced composites: $W_{\text {init }}$ represents $45 \%$ of the total absorbed energy. However, the $F_{\max }$ value of the satin fabric composite is $30 \%$ lower than that of UD composite. This results in a total absorbed energy $W_{\text {total }}$ for the AS4/APC2 composite that is twice as high as for the satin composite. 


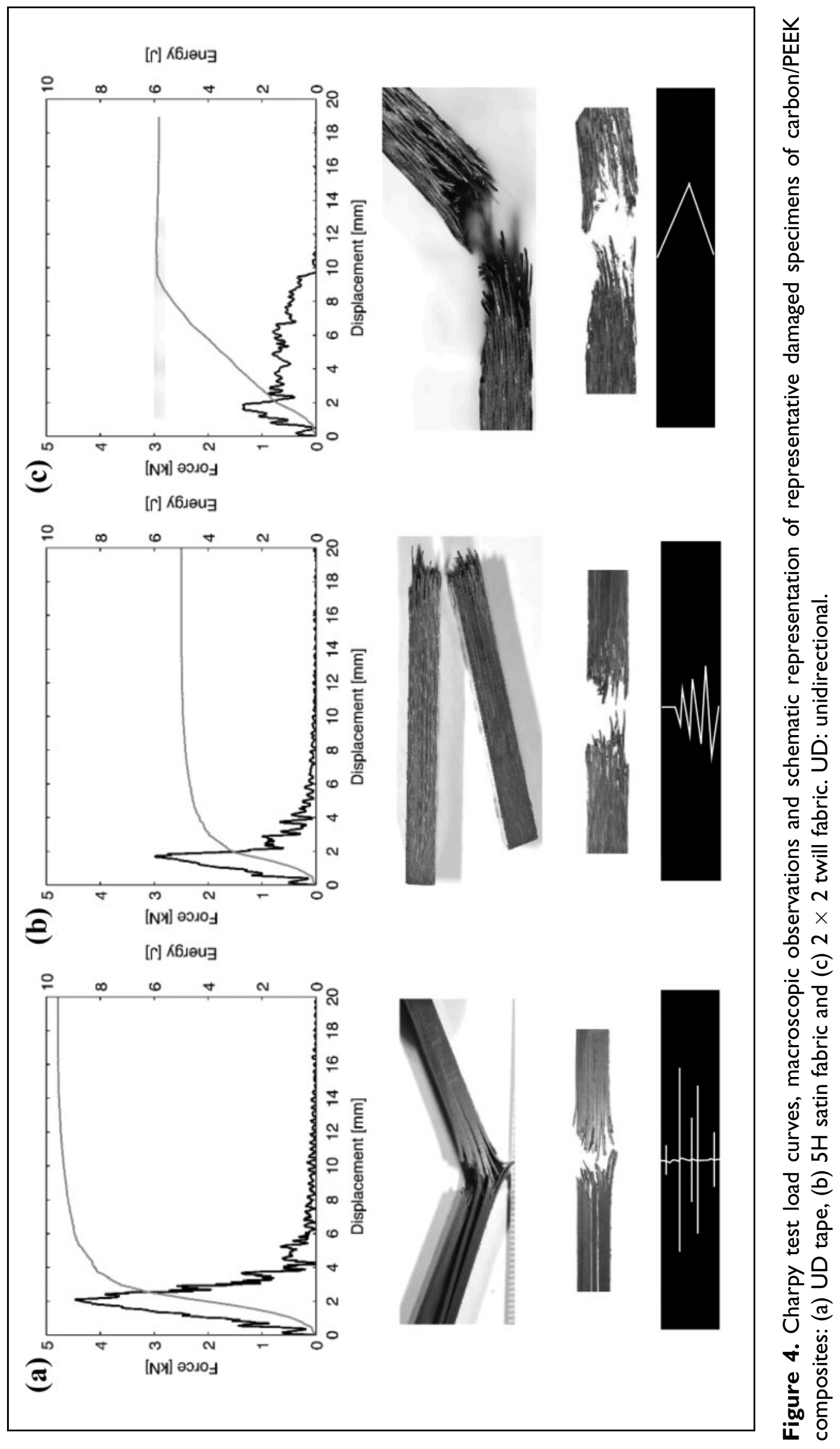




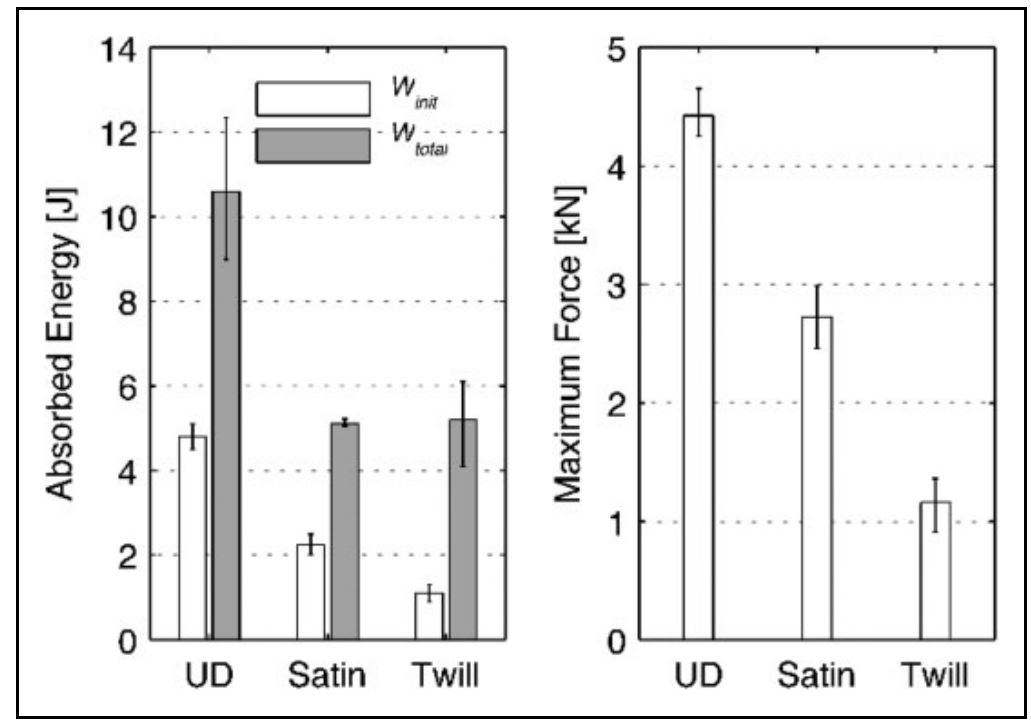

Figure 5. Partial and total absorbed energies $W_{\text {init }}$ and $W_{\text {total }}$ (left) and maximum force at peak $F_{\max }($ right) measured on the carbon/PEEK composites.

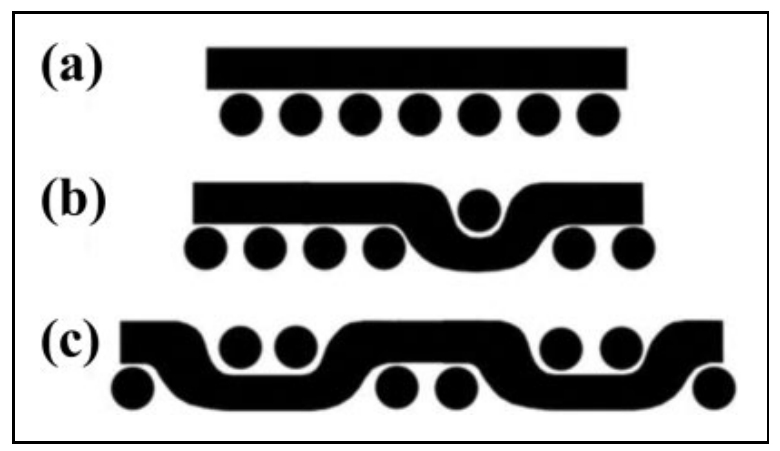

Figure 6. Schematic representation of a ply cross section of each reinforcement highlighting the difference of tow crimp in the reinforcement weaves investigated: (a) UD, (b) $5 \mathrm{H}$ satin and (c) $2 \times$ 2 twill.

UD: unidirectional.

For the $2 \times 2$ twill laminate, the absorbed energy $W_{\text {init }}$ during the first loading phase only represented $17 \%$ of the total absorbed energy. As a consequence, although they exhibited very different behaviours, the total energy absorbed by the composites made with fabrics was of the same order (5 J, Figure 6).

Discussion on influence of weave pattern. According to the previous results, both the load-displacement behaviours and the failure modes during Charpy impact tests can be related on one hand to the plies interpenetration and on the other to the crimp ratio.

- Delamination is a damaging mechanism observed in UD laminates, but is limited in fabric-reinforced laminates because of the interpenetration of fabric plies: the chaotic interface between any two plies limits the propagation of delamination. ${ }^{1}$ This explains why delamination is not observable in fabric-reinforced composites while it appeared as a significant damaging mechanism in AS4/APC2 laminate. 
- The crimp ratio is the ratio of the yarn length to the length of fabric produced from that yarn. ${ }^{26}$ In balanced fabrics, this ratio is all the higher when warp and weft interlace per unit length of fabric. It is known to largely influence the mechanical properties of fabrics, particularly the tensile modulus, ${ }^{27,28}$ but also the resistance of the yarns in tension. ${ }^{29,30}$ In AS4/APC2 composite, all the carbon yarns are straight and aligned within the plies which give a crimp ratio equal to 1 . The tensile modulus and strength of the AS4/APC2 is therefore higher than in $5 \mathrm{H}$ satin fabric and even higher than that of $2 \times 2$ twill fabric and the $F_{\max }$ value is governed by the failure of carbon yarns in tension. As the warp tows and the weft tows interlace twice every five yarns and twice every two yarns, this ratio increases in $5 \mathrm{H}$ satin and even more in $2 \times 2$ twill fabrics (Figure 6).

The $F_{\max }$ value is governed by the failure of carbon yarns. This failure is due to the tension of carbon yarns but also of their shear. The distribution between tension loading and shear loading depends on the crimp level of the fabrics in the laminates. In fabrics, the higher the crimp ratio, the higher is the shear loading of the yarns and the lower is $F_{\max }$. For the $2 \times 2$ twill laminate, even if $F_{\max }$ is weak, the flexibility of both the plies and the structure induces a diffuse fracture. This progressive failure still allows the material to absorb a significant quantity of energy before total fracture and ejection from the anvils. This behaviour (low $F_{\max }$ and high energy absorption) can be interesting in armour applications. From these observations, it may be interesting to study the influence of the nature of the fibres to optimize this process.

\section{Effect of fibre nature}

Results. The influence of fibre nature on the impact behaviour of $5 \mathrm{~mm}$ thick quasiisotropic composites was analysed using the same methodology as for the comparison of the carbon-reinforced composites. Figure 7 shows the Charpy impact data and a photograph of a representative impacted sample for each type of fibre: carbon (Figure 7(a)), glass (Figure 7(b)), basalt (Figure 7(c)), aramid (Figure 7(d)) and PBO (Figure 7(e)). These five fibres cover the main families of reinforcement: non-siliceous inorganic fibre (carbon), siliceous inorganic (mineral) fibres (glass and basalt) and organic fibres (aramid and PBO). Figure 8 shows micrographic observations of the damaged areas.

As shown in Figure 7(b) and (c), the $2 \times 2$ twill glass and basalt composites exhibited a loading curve similar to the carbon satin and carbon UD laminates: a distinct peak load followed by prompt failure. In both cases, the specimens broke under the Charpy hammer and the fractures were principally characterized by fibre breakage. The effect of fabric weave observed for carbon-reinforced laminates was therefore different for mineral fibres. The unstable propagation of the fracture was smoother for carbon than for the mineral fibres.

The impacted samples of glass and basalt fibres-reinforced composites exhibit a more localized fracture area than the carbon material (Figure 8(a) and (b)). No delamination is observable which agrees with the previous analysis of the influence of weave on Charpy impact behaviour. 


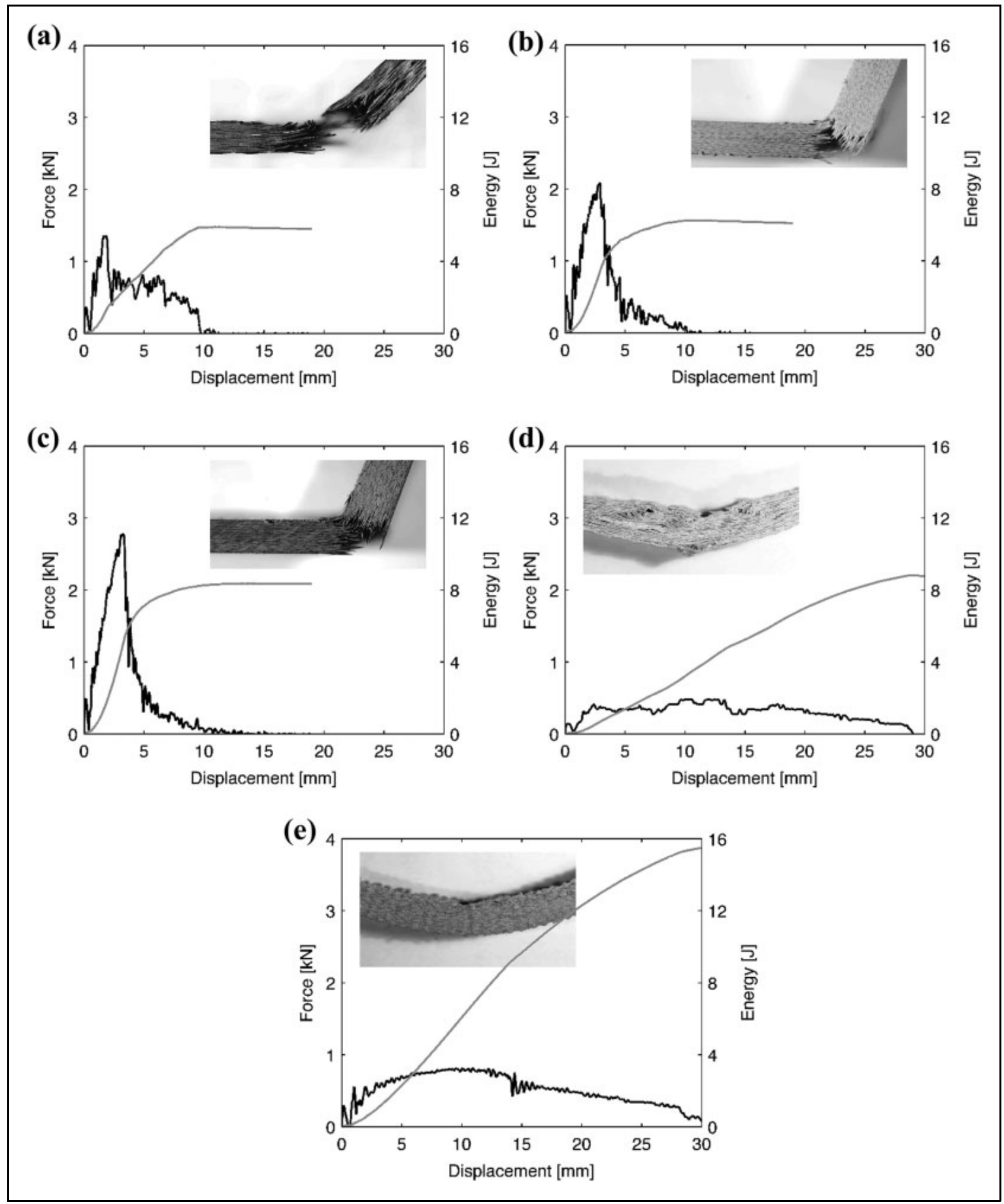

Figure 7. Charpy test load curves on representative PEEK composite specimens fabricated with $2 \times 2$ twill fabrics: (a) carbon, (b) glass, (c) basalt, (d) aramid and (e) PBO. PBO: poly(P-phenylene-2,6-benzobisoxazole).

Unlike the inorganic fibre-reinforced composites, the composites with organic fibres did not break during the Charpy impact test (Figure 8(c) and (d)). As shown on the load/ displacement curves of aramid and PBO, the resistance to impact and the energy absorption occurred during $30 \mathrm{~mm}$ of displacement. This displacement corresponds to 


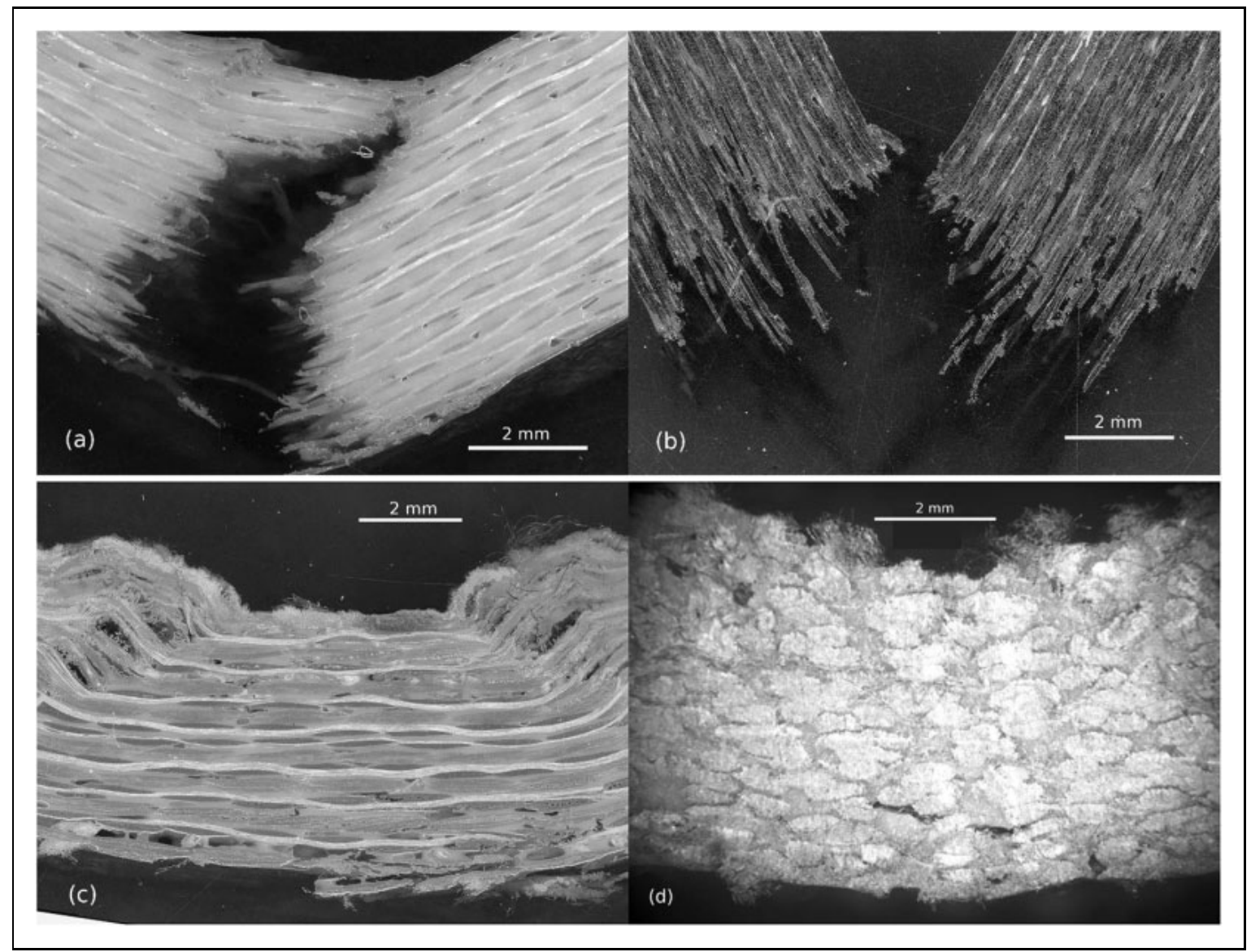

Figure 8. Microscopic observations of the damaged area of Charpy specimens reinforced with glass (a), basalt (b), aramid (c) and PBO (d) fibres. PBO: poly(P-phenylene-2,6-benzobisoxazole).

the maximum bending of the specimen (length of $70 \mathrm{~mm}$ ) before it is ejected from the anvils (distance of $40 \mathrm{~mm}$ ).

The load curves obtained for these materials also contrast with those of composites with inorganic fibres by their shape. Although the maximum load $F_{\max }$ can be identified, the Charpy test curves are flattened, with a load constantly below $1 \mathrm{kN}$.

Even if the samples were ejected before fracture, damage occurred during the impact (Figure 8(c) and (d)). In both aramid- and PBO-reinforced materials, the impact induced matrix microcracking. In the case of aramid, it led to the apparition of shear bands starting from the impacted side and to a few fibre failures on the non-impacted side (Figure 8(c)).

Discussion on influence of fibre nature. The chart in Figure 9 compares the different types of fibres in regard to the Charpy impact characteristic properties, that is, the total absorbed energy $W_{\text {total }}$, the maximum force $F_{\text {max }}$ and the absorbed energy at peak $W_{\text {init }}$. Three behaviours can be distinguished, corresponding to the three different families of fibres: the organic population, which is characterized by high but progressive energy absorption (low $F_{\max }$ ), the mineral population, which has brittle behaviour but a 


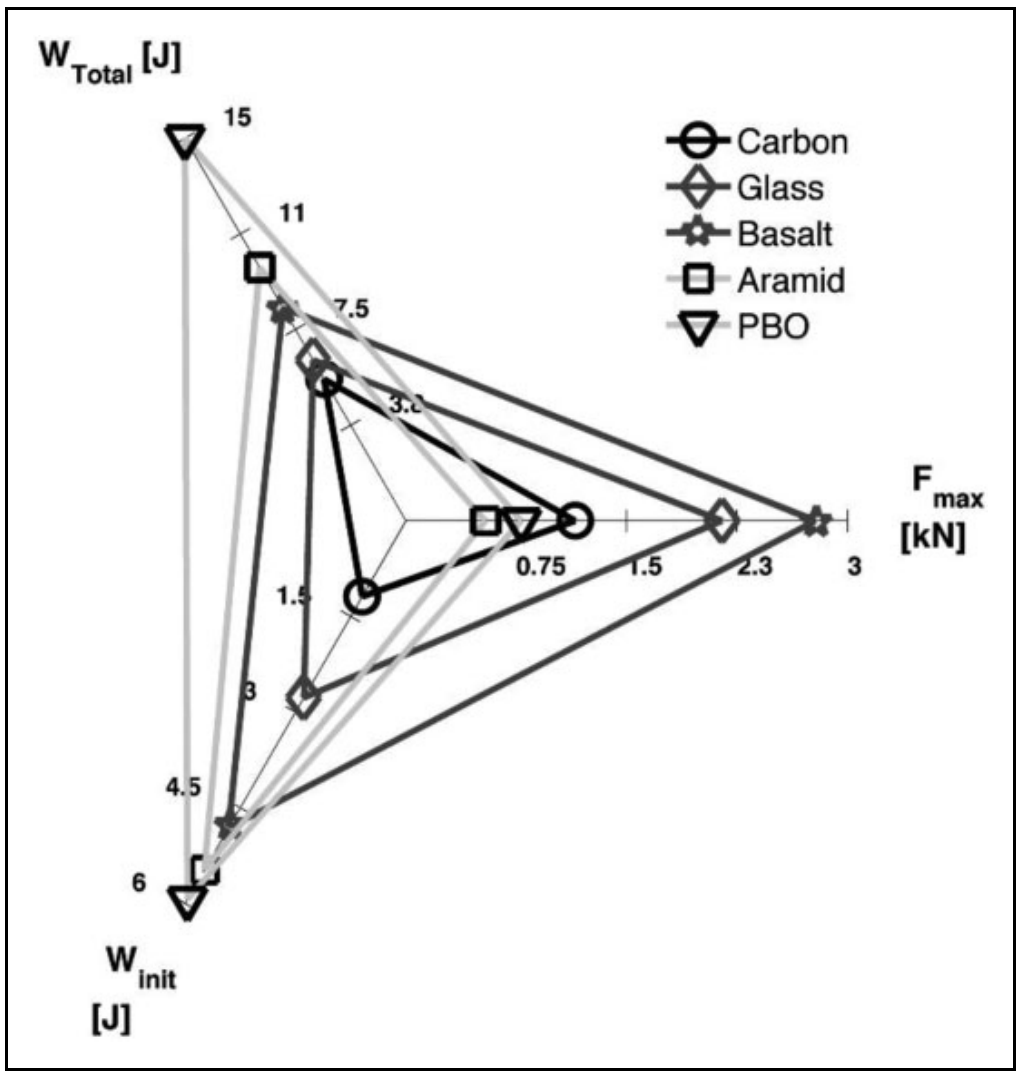

Figure 9. Comparison of characteristic properties of Charpy impacted specimens.

Table 3. Properties of inorganic and organic fibres.

\begin{tabular}{lccccc}
\hline & Carbon & Glass & Basalt & Aramid & PBO \\
\hline Elastic modulus (GPa) & 235 & 73 & 86 & 120 & 180 \\
Strength (GPa) & 4.4 & 2.2 & 2.8 & 3.6 & 5.8 \\
Strain at break (\%) & 1.7 & 3.5 & 3.1 & 2.8 & 3.5 \\
Density & 1.78 & 2.60 & 2.67 & 1.45 & 1.54 \\
\hline
\end{tabular}

PBO: poly(p-phenylene-2,6-benzobisoxazole).

reasonable absorbed energy due to a high $F_{\max }$ and the non-siliceous inorganic population, which shows limited performance (low $W_{\text {total }}$ and $F_{\max }$ ).

Many factors can influence the Charpy impact properties of composite materials but, in the present case, as it corresponds to the main families of fibres, this classification into three main populations must be correlated with the intrinsic properties of the fibres. The tensile properties of the fibres are summarized in Table 3 and, for the sake of clarity, Figure 10 proposes a graphical representation of the mechanical behaviour of the different types of fibres. The ply thickness was also considered in the comparison.

Carbon fibres, which have the highest stiffness, differ from the other fibres by their low deformability. In contrast, glass and basalt fibres exhibit poor stiffness and strength but a strain at rupture that is twice as high as that of carbon. Organic fibres, aramid and 


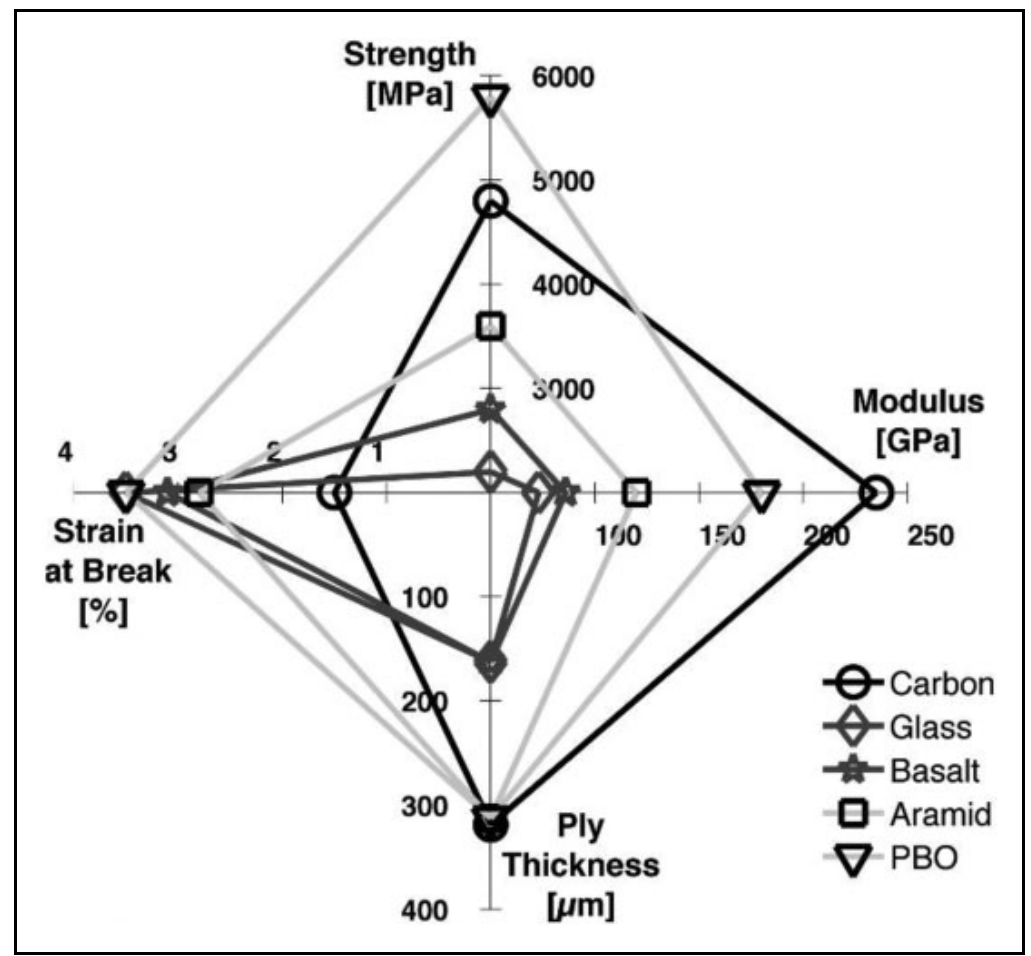

Figure 10. Mechanical properties of the five types of fibres and ply thickness in composite samples.

PBO, show an interesting compromise of stiffness, strength and strain at rupture. In particular, PBO fibres have a modulus only $23 \%$ lower than carbon and the highest strength and deformability.

The ply thickness of carbon, aramid and PBO composites is similar. The $5 \mathrm{~mm}$ thick laminates were fabricated with the same number of plies, and it can be considered that the specimens and fabric plies carried the same loading forces during Charpy impact. The difference of impact behaviour and composite resistance was thus only due to the difference of the mechanical properties of the fibres. The absence of a loading peak for organic fibre-reinforced composite may then be due to the lower stiffness of these laminates because of the lower Young modulus of the fibres. The totally different energy absorption process, progressive carbon fibre failure versus specimen bending with matrix cracking for organic fibres, may be the consequence of the differences in deformability and strength of the organic fibres.

Since the mineral fibre-reinforced composites comprise twice as many plies of fabric as the other composites, the analysis of their mechanical response to Charpy impact cannot be only based on the fibre performances. Thinner plies induce a lower crimp ratio and therefore a higher stiffness of the specimen's structure. The competition between the structural effect, governed by the ply thickness and yarn crimp in the fabric, and the intrinsic mechanical performance of the fibres led to an absorbed energy that was significantly higher in the case of mineral reinforcements than the energy absorbed by the carbon composite. The brittle behaviour observed for these composites and the moderate mechanical properties of glass and basalt 
fibres then suggest that the structure has a dominant effect on the composite reaction to Charpy impact loading.

\section{Conclusions}

The comparison of different carbon weaves and fibre types by means of Charpy impact tests has highlighted two main behaviours that result from the complementarity of yarn crimp, delamination onset, ply thickness and properties of the fibre.

In the case of AS4/APC2, the low yarn crimp, the small ply thickness and the rigidity of carbon produce a very stiff composite that leads to a tensile loading of the reinforced fibres during impact. This loading mode induces brittle fracture of the specimens due to the apparition of delamination and fibre failure.

The slight increase of yarn waviness in $5 \mathrm{H}$ satin fabric and the decrease of ply thickness in glass and basalt fabrics lead to the same brittle behaviour. The effect of crimp seems to be a dominant parameter controlling the failure mode of the composites when delamination cannot occur.

On the contrary, specimens with low stiffness, that is, composites made of thick $2 \times 2$ twill fabrics, can bend. For the carbon specimen, the load applied during the impact leads to a progressive but total fracture of the specimen. In the same configuration, organic fibres demonstrated their ability to deform without rupture and to absorb energy during impact. The fibres, and therefore the specimens, did not break neither in shear nor in bending. The ability to deform without shear sensitivity appeared to be more efficient for energy absorption than the stiff resistance to impact.

In particular, PBO absorbed 50\% more energy than AS4/APC2 during Charpy impact testing. This organic fibre is thus an interesting alternative to aramid for composite armours, when deflection is allowed for projectile protection.

This comparative study has pointed out the effect of crimp and ply thickness on the deformation mechanisms of composites. However, no relation could be found between the local loading applied to the fibres and their multiaxial intrinsic properties. Further investigations are thus required to better understand the origin of impact resistance. In particular, the dynamic behaviour and the shear strength of the fibres remain poorly known.

\section{Declaration of Conflicting Interests}

The author(s) declared no potential conflicts of interest with respect to the research, authorship and/or publication of this article.

\section{Funding}

The author(s) received no financial support for the research, authorship and/or publication of this article.

\section{References}

1. Abrate S. Impact on composite structures. Cambridge: Cambridge University Press, 1998. 
2. Richardson MOW and Wilsheart MJ. Review of low-velocity impact properties of composite materials. Compos A Appl Sci Manuf 1996; 27(12): 1123-1131.

3. Bouvet C, Castanié B, Bizeul M, et al. Low velocity impact modelling in laminate composite panels with discrete interface elements. Int J Solids Struct 2009; 46: 2809-2821.

4. Bessard E. Matériaux composites structuraux à base PEEK élaborés par thermocompression dynamique: relation procédé-propriétés. $\mathrm{PhD}$ thesis, University of Toulouse, 2012.

5. Bismarck A, Hofmeier M and Dörner G. Effect of hot water immersion on the performance of carbon reinforced unidirectional poly(ether ether ketone) (PEEK) composites: stress rupture under end-loaded bending. Compos A Appl Sci Manuf 2007; 38: 407-426.

6. Tennyson RC and Lamontagne C. Hypervelocity impact damage to composites. Compos $A$ Appl Sci Manuf 2000; 31: 785-794.

7. Vieille B, Albouy W and Taleb L. Investigations on stamping of C/PEEK laminates: influence on meso-structure and macroscopic mechanical properties under severe environmental conditions. Compos B Eng 2014; 63: 101-110.

8. Bishop SM. The mechanical performance and impact behaviour of carbon-fibre reinforced PEEK. Compos Struct 1985; 3: 295-318.

9. Dorey G, Bishop SM and Curtis PT. On the impact performance of carbon fibre laminates with epoxy and PEEK matrices. Compos Sci Technol 1985; 23: 221-237.

10. Vieille B, Casado VM and Bouvet C. Influence of matrix toughness and ductility on the compression-after-impact behavior of woven-ply thermoplastic- and thermosettingcomposites: a comparative study. Compos Struct 2014; 110: 207-218.

11. Vieille B, Casado VM and Bouvet C. About the impact behavior of woven-ply carbon fiberreinforced thermoplastic- and thermosetting-composites: a comparative study. Compos Struct 2013: 101: 9-21.

12. Abdulhamid H, Bouvet $\mathrm{C}$, Michel L, et al. Influence of internally dropped-off plies on the impact damage of asymmetrically tapered laminated CFRP. Compos A Appl Sci Manuf 2015; 68: $110-120$.

13. Hongkarnjanakul N, Bouvet $\mathrm{C}$ and Rivallant $\mathrm{S}$. Validation of low velocity impact modelling on different stacking sequences of CFRP laminates and influence of fibre failure. Compos Struct 2013; 106: 549-559.

14. Mohmmed R, Zhang F, Sun B, et al. Finite element analyses of low-velocity impact damage of foam sandwiched composites with different ply angles face sheets. Mater Des 2013; 47: $189-199$.

15. Adams DF and Perry JL. Instrumented Charpy impact tests of several unidirectional composite materials. Fibre Sci Technol 1975; 8: 275-302.

16. Adams DF and Perry JL. Low level Charpy impact of graphite epoxy hybrid composites. J Eng Mater Technol ASME 1977; 99: 257-263.

17. Arifin AMT, Abdullah S, Rafiquzzaman MD, et al. Investigation of the behaviour of a chopped strand mat/woven roving/foam-Klegecell composite lamination structure during Charpy testing. Mater Des 2014; 59: 475-485.

18. Li D, Jiang N, Zhao C, et al. Charpy impact properties and failure mechanism of 3D MWK composites at room and cryogenic temperatures. Cryogenics 2014; 62: 37-47.

19. Martin E, Macke T, Quenisset JM, et al. Analysis of impact properties of 3D-carbon-carbon composite materials by the instrumented Charpy test. Compos Sci Technol 1986; 26: 185-197.

20. Kalthoff JF. Characterization of the dynamic failure behaviour of a glass-fiber/vinyl-ester at different temperatures by means of instrumented Charpy impact testing. Compos B Eng 2004; 35: 657-663. 
21. Hufenbach W, Marques Ibraim F, Langkamp A, et al. Charpy impact tests on composite structures - an experimental and numerical investigation. Compos Sci Technol 2008; 68: 2391-2400.

22. Hufenbach W, Petrinic N, Bohm R, et al. Multidisciplinary damage analysis of textilereinforced composites for impact and crash applications. J Nondestruct Test Bd 2006; 12: 11.

23. Ghasemnejad H, Furquan ASM and Mason PJ. Charpy impact damage behaviour of single and multi-delaminated hybrid composite beam structures. Mater Des 2010; 31: 3653-3660.

24. Ghasemnejad H, Soroush VR, Mason PJ, et al. To improve impact damage response of single and multi-delaminated FRP composites using natural Flax yarn. Mater Des 2012; 36: 865-873.

25. Fernandez-Canteli A, Arguelles A, Vina J, et al. Dynamic fracture toughness measurements in composites by instrumented testing: influence of aging. Compos Sci Technol 2002; 62: $1315-1325$.

26. Adanur S. Handbook of weaving. Boca Raton: CRC Press/Taylor \& Francis, 2002.

27. Abot JL, Gabbai RD and Harsley K. Effect of woven fabric architecture on interlaminar mechanical response of composite materials: an experimental study. $J$ Reinf Plast Compos 2011; 30: 2003-2014.

28. Scida D, Aboura Z, Benzeggagh ML, et al. A micromechanics model for 3D elasticity and failure of woven-fibre composite materials. Compos Sci Technol 1999; 59: 505-517.

29. Osada T, Nakai A and Hamada H. Initial fracture behavior of satin woven fabric composites. Compos Struct 2003; 61: 333-339.

30. Duplessis Kergomard Y, Renard J, Thionnet A, et al. Intralaminar and interlaminar damage in quasi-unidirectional stratified composite structures: experimental analysis. Compos Struct Technol 2010; 70: 1504-1512. 